Original Research Article

\title{
Drug utilization pattern of psychotropic medicines in tertiary care centre of Bastar Region, Chhattisgarh, India
}

\author{
Ratna Agrawal', Marium K. A. ${ }^{2}$, Raj Kumar Sharma ${ }^{1 *}$, Sanat Kumar Sharma ${ }^{1}$, \\ Mahendra Kumar Jaiswal ${ }^{1}$
}

${ }^{1}$ Department of Pharmacology, Late Baliram Kashyap Memorial Government Medical College,

Dimrapal, Jagdalpur, Chhattisgarh, India

${ }^{2}$ Department of Psychiatry, Late Baliram Kashyap Memorial Government Medical College, Dimrapal, Jagdalpur,

Chhattisgarh, India

Received: 04 June 2019

Revised: 29 June 2019

Accepted: 03 July 2019

*Correspondence to:

Dr. Raj Kumar Sharma,

Email: pinkindiaraj@gmail.com

Copyright: (C) the author(s), publisher and licensee Medip Academy. This is an openaccess article distributed under the terms of the Creative Commons Attribution NonCommercial License, which permits unrestricted noncommercial use, distribution, and reproduction in any medium, provided the original work is properly cited.

\begin{abstract}
Background: With the changing lifestyle, the incidence of psychiatric illness is increasing day by day. And the mental illnesses not only affect the social and personal life but also adds additional economic burden affecting quality of life of the person. So, proper diagnosis and management of psychiatric illnesses is utmost important. So, keeping this in mind, the present study has been conducted to evaluate drug utilization pattern of psychotropic medicines in tertiary care centre of Bastar region.

Methods: After obtaining approval from Institutional Ethics Committee, present study was conducted in 237 patients for a period of 3 months from February 2019 to April 2019. The data of patients attending psychiatry OPD was collected in a structured case record form. The data were analysed using graph pad prism version 6.0 .

Results: Out of total 237 patients, males 136(57.38\%) outnumbered females 101 (42.62\%). The major psychiatric illness reported was schizophrenia (45.99\%) followed by bipolar affective disorder (16\%) and generalized anxiety disorder $(14.35 \%)$. Average number of psychotropic drugs per prescription was $1.74 \pm 1.02$. The percentage of drugs prescribed from state Essential drug List (EDL) was $93.05 \%$.

Conclusions: Overall, the principles of rational prescribing was tried to be maintained, as polypharmacy has been avoided and most of the drugs were prescribed from the state EDL. The use of generic drugs should be increased to make prescriptions more rational and to cut down the cost of the therapy which may be helpful in increasing the quality of life of the patients.
\end{abstract}

Keywords: DDD, Drug utilization pattern, PDD, Prescribing pattern, Schizophrenia

\section{INTRODUCTION}

Mental health is an integral part of health and is more than the absence of mental illnesses. ${ }^{1}$ It refers to a broad array of activities directly or indirectly related to the mental wellbeing, prevention of mental disorders, and treatment and rehabilitation of people affected by mental disorders. ${ }^{1}$ Of the top ten health conditions contributing to the Disability Adjusted Life Years (DALYs), four are psychiatric disorders. ${ }^{2,3}$ In India, WHO estimates that the burden of mental health problems is of the tune of 2,443 DALYs per 100,000 population, and the age-adjusted suicide rate per 100,000 population is $21.1{ }^{1}$ It is estimated that, in India, the economic loss, due to mental health conditions, between 2012-2030, is 1.03 trillions of 2010 dollars. ${ }^{1}$

Mental illness is associated with high levels of health service utilization and associated costs, and in developing countries these costs are mostly paid by the patient. ${ }^{2,4}$ So, the proper treatment of mental disorders is utmost 
important, which should be associated with availability and access to cost effective psychotropic medicines with adequate prescribing and consultation by experienced psychiatrist. And which can be evaluated by the drug utilization studies (DUS), defined by WHO as "The marketing, distribution, prescription and use of drugs in a society, with special emphasis on the resulting medical, social and economic implications." 5

Keeping this in mind, the present study was conducted to evaluate drug utilization pattern of psychotropic medicines in tertiary care psychiatry outdoor along with pattern of distribution of various psychotropic disorders in the Bastar region.

\section{METHODS}

After obtaining the approval from the Institutional Ethics Committee the present cross sectional study was conducted in 237 patients for a period of 3 months in the Department of Pharmacology and Psychiatry from February 2019 to April 2019. The data of patients attending the Psychiatry OPD was collected in a structured case record form. Prescriptions of patients of both sexes and all ages, suffering from a psychotropic illness and started on at least one psychotropic medication, were included. The types of data collected were; patient's demographic profile including age, sex, educational status; diagnosis; prescription details like number of drugs per prescription, name of the drug (brand/ generic), any fixed dose combination, dosage form and dose, number of drugs prescribed from WHO- EML and state essential drug list etc.

\section{Data and Statistical analysis}

The drugs were classified according to the anatomical therapeutic chemical (ATC) classification system. As per ATC classification system, the medicines are divided into different groups according to the organ or system on which they act and as per their chemical, pharmacological and therapeutic properties. ${ }^{6,7}$ The prescribed daily dose (PDD) was calculated by taking the average of the daily doses of psychotropic drugs. PDD was calculated for the most frequently prescribed drugs in various psychotropic disorders using following formula; ${ }^{5}$

PDD $=$ Quantity of drug dispensed X strength of drug Number of cases prescribed

PDD is the average daily dose prescribed as obtained from a representative sample of prescriptions. ${ }^{5}$ The PDD can be determined from studies of prescriptions or medical or pharmacy records. ${ }^{5}$

For the drugs where the recommended dosage differs from one indication to another (e.g. antipsychotics), it is important to link the diagnosis to the PDD. ${ }^{5}$ But PDD does not necessarily reflect actual drug utilization, as some prescribed medications are not dispensed, and the patient does not always take all the medications that are dispensed..$^{5}$ The DDD for a drug is assumed average maintenance dose per day for a drug used as a main indication in adults. ${ }^{5}$

The data were analysed using graph pad prism version 6.0. Patient's demographic data were presented as mean \pm standard deviation (SD).

\section{RESULTS}

\section{Demographic profile of study participants}

A total of 237 patients were included in the study, of which $136(57.38 \%$ ) were male and remaining $101(42.62 \%)$ were females respectively.

The age range was 11-74 years. The relative distribution of different psychiatric disorders in different age group and gender is presented in Table 1. The educational level of most of the patients was unsatisfactory, as most of them $136(57.38 \%)$ were educated only up to $8^{\text {th }}$ standard, $61(25.74 \%)$ up to $12^{\text {th }}$ standard and remaining $40(16.87 \%)$ were graduate.

Table 1: Age and gender wise distribution of psychiatric disorders.

\begin{tabular}{|lllllll|}
\hline & \multicolumn{2}{l}{ Age (years) } & & \multicolumn{2}{c|}{ Gender } \\
Psychiatric disorders & $\mathbf{0 - 2 5}$ & $\mathbf{2 6 - 5 0}$ & $\mathbf{5 1 - 7 5}$ & $\mathbf{7 5}$ & Male & Female \\
\hline Schizophrenia and other psychoses $(\mathrm{n}=109)$ & 39 & 56 & 13 & 01 & 56 & 53 \\
\hline BPAD $(\mathrm{n}=38)$ & 7 & 26 & 5 & -- & 19 & 19 \\
\hline GAD $(\mathrm{n}=34)$ & 8 & 20 & 6 & -- & 19 & 15 \\
\hline Substance induced mood disorders(SIMD) $(\mathrm{n}=19)$ & 4 & 15 & -- & -- & 19 & -- \\
\hline Depression $(\mathrm{n}=16)$ & 3 & 10 & 3 & -- & 10 & 06 \\
\hline Dissociation disorders $(\mathrm{n}=6)$ & 01 & 05 & -- & -- & 03 & 03 \\
\hline Somatization disorders $(\mathrm{n}=4)$ & -- & 04 & -- & -- & 02 & 02 \\
\hline Others $(\mathrm{n}=11)$ & 07 & 04 & -- & -- & 08 & 03 \\
\hline Total $(\mathrm{n}=237)$ & 69 & 140 & 27 & 01 & 136 & 101 \\
\hline
\end{tabular}




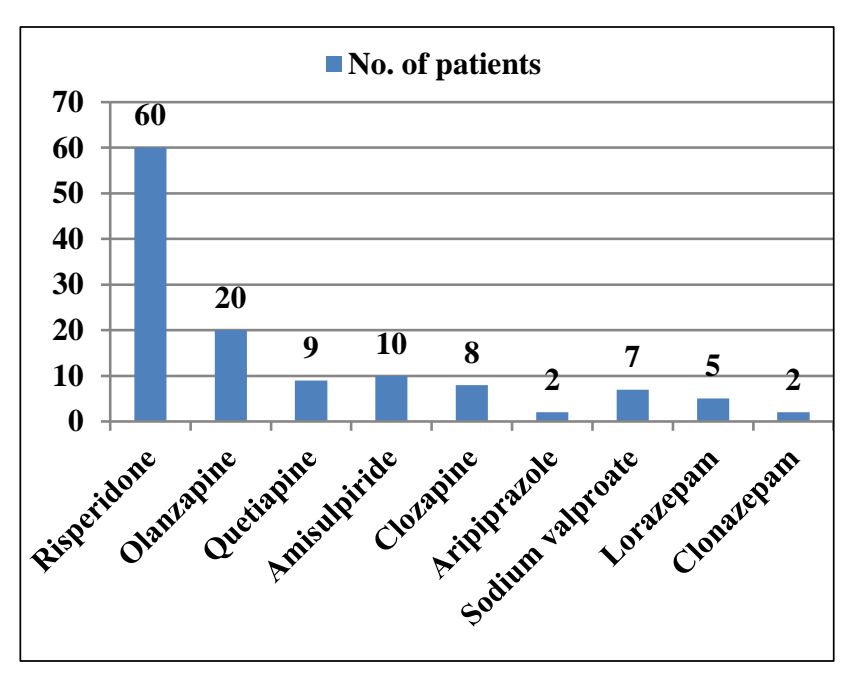

Figure 1: Prescribing pattern of psychotropic drugs in schizophrenia and other psychoses.

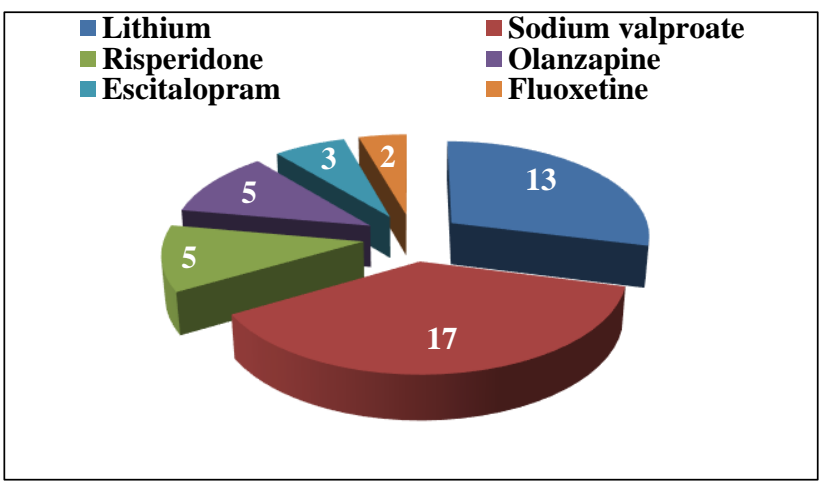

Figure 2: Prescribing pattern of psychotropic drugs in various mood disorders.

\section{Pattern of psychiatric disorders and psychotropic drug used}

The major psychiatric disorder reported was schizophrenia, which included 109(45.99\%) prescriptions followed by bipolar affective disorder (BPAD) $16 \%$, generalized anxiety disorder (GAD) $14.35 \%$, substance induced mood disorders (SIMD) $8.01 \%$, depression $6.75 \%$, somatisation and dissociation disorders and others like obsessive compulsive disorder (OCD), mental retardation, attention deficit hyperkinetic disorders etc, as shown in Table 1 along with demographic profile.

Total 15 psychotropic drugs were prescribed in outdoor patients. Out of them, 6 drugs belonged to antipsychotic class (risperidone, olanzapine, clozapine, aripiprazole, quetiapine and amisulpride), 2 drugs (lithium and sodium valproate) from mood stabilizers group, 5 drugs were from antidepressant group (escitalopram, mirtazapine, vilazodone, fluoxetine and amitriptyline) and 2 were benzodiazepines (lorazepam and clonazepam).

The prescription pattern of various psychotropic drugs in major psychotropic illness found (schizophrenia, BPAD and GAD), is presented in Figure 1, 2 and 3 respectively.

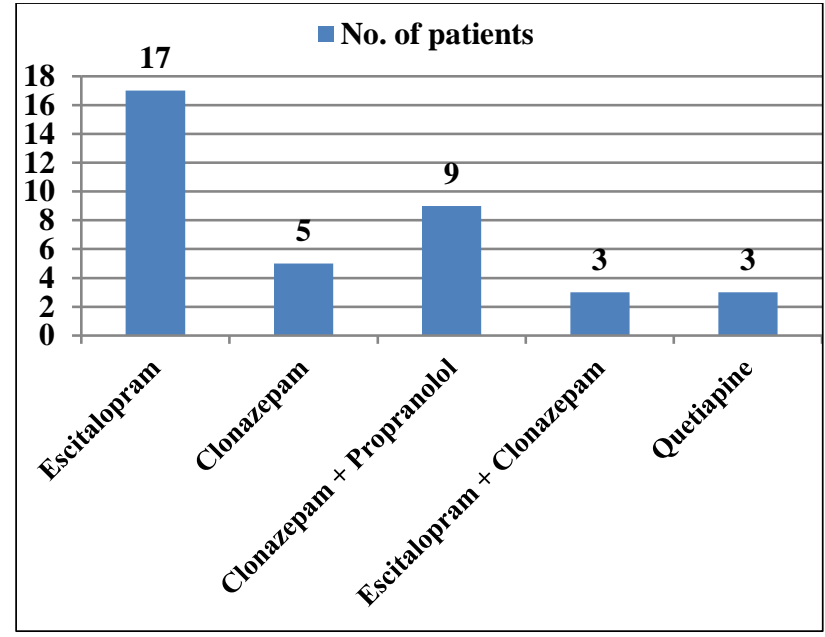

Figure 3: Prescribing pattern of psychotropic drugs in various anxiety disorders.

\section{Analysis of prescribing pattern according to WHO drug use indicators}

The 237 prescriptions consisted of 480 drugs, of which 360 were psychotropic drugs. The other drugs commonly coprescribed were anticholinergics, antihistamines, muscle relaxants, vit B complex, multivitamins, disulfiram and propranolol(anxiety disorders). Each prescription consisted of average 2 drugs and not more than four drugs. The fixed dose combination prescribed were trihexyphenidyl $2 \mathrm{mg}+$ risperidone $6 \mathrm{mg}$, escitalopram 10mg+clonazepam $\quad 0.5 \quad \mathrm{mg}, \quad$ clonazepam $0.5 \mathrm{mg}+$ propranolol 20mg. The psychotropic drug use pattern is summarized in Table 2.

\section{Pattern of major psychotropic drug used in the study as per ATC/DDD classification}

The PDD/DDD ratio of most frequently prescribed drugs in various psychiatric disorders has been presented in Table 3.

Table 2: Psychotropic drug use pattern according to WHO prescribing pattern indicators.

\begin{tabular}{|ll|}
\hline WHO drug use indicators & Results \\
\hline $\begin{array}{l}\text { Average number of drugs per } \\
\text { prescription (Mean } \pm \text { SD) }\end{array}$ & $2.20 \pm 1.01$ \\
\hline $\begin{array}{l}\text { Average number of psychotropic } \\
\text { drugs per prescription } \\
\text { (Mean } \pm \text { SD) }\end{array}$ & $1.74 \pm 1.02$ \\
\hline $\begin{array}{l}\text { Percentage of prescriptions with } \\
\text { psychotropic FDCs }\end{array}$ & $36 / 237(15.19 \%)$ \\
\hline $\begin{array}{l}\text { Percentage of drugs prescribed by } \\
\text { generic name }\end{array}$ & $100 / 480(20.83 \%)$ \\
\hline $\begin{array}{l}\text { Percentage of psychotropic drugs } \\
\text { prescribed from WHO-EML 2017 }\end{array}$ & $120 / 360(33.33 \%)$ \\
\hline $\begin{array}{l}\text { Percentage of psychotropic drugs } \\
\text { prescribed from Chhattisgarh } \\
\text { (State) Essential Drug List } 2016\end{array}$ & $335 / 360(93.05 \%)$ \\
\hline
\end{tabular}


Table 3: The list of psychotropic drug used along with ATC code and PDD/DDD ratio.

\begin{tabular}{|lllll|}
\hline Drug & ATC code & DDD $(\mathbf{m g})$ & PDD $(\mathbf{m g})$ & PDD/DDD \\
\hline Risperidone & N05AX08 & 5 & 4 & 0.8 \\
\hline Olanzapine & N05AH03 & 10 & 10 & 1 \\
\hline Clozapine & N05AH02 & 300 & 100 & 0.33 \\
\hline Lithium & N05AN01 & $24 \mathrm{mmol}$ & $7.83 \mathrm{mmol}^{*}$ & 0.33 \\
\hline Sodium valproate & N03AG01 & 1500 & 608.33 & 0.41 \\
\hline Escitalopram & N06AB10 & 10 & 10 & 1 \\
\hline Clonazepam & N03AE01 & 8 & 1.77 & 0.22 \\
\hline
\end{tabular}

*For conversion of $\mathrm{mg} / \mathrm{l}$ to $\mathrm{mmol}$, formula used was (taken by the study conducted by Thakkar et al,) - mg/l x 0.144=mmol/1 x 6.94

\section{DISCUSSION}

The present study showed that the males visited Psychiatry OPD more as compared to females, which is in contrast to the study conducted by Thakkar et al. ${ }^{2}$ The reason behind same may be as most of the patients in this study belonged to low socio-economic status and tribal region where the living condition of females is still not satisfactory and they also don't want to visit to the doctors because of the local tribal beliefs.

The age group mainly affected by psychiatric illness is between 26-50 years, which is very similar to other studies. $^{2,8,9}$ The main psychotropic illness found in the present study was schizophrenia, similar findings has also been seen in the study conducted by Piparva et al. ${ }^{8}$

\section{Analysis of prescribing pattern}

The average number of psychotropic drugs per prescription was $1.74 \pm 1.02$, which was lower than the other studies. ${ }^{2,10}$ The reason behind the same may be that only few drugs are available in hospital drug store and the patients need to buy the rest from outside, so the polypharmacy has been avoided as many patients in the study belonged to low socio-economic status. In spite of the government order, most of the drugs have been prescribed by brand name in present study, which was in contrast to the study conducted by Thakkar et al. ${ }^{2}$ The reason behind same may be that hospital drug store has very few drugs and patients has to purchase most of them from outside pharmacies, so to attain the desired therapeutic response the single brand name drug is needed to prescribe. Most of the drugs were prescribed from the state essential drug list (C.G.EDL 2016) as compared to WHO-EML 2017, because the prescription pattern differs from state to state depending upon the availability of that particular drug according to government issued essential drug list.

\section{Observed drug use pattern in schizophrenia}

The present study showed that most commonly prescribed drugs were atypical antipsychotics as compared to typical one which differs from the study conducted by Thakkar et al. ${ }^{2}$ This is because the typical antipsychotics are associated with more extrapyramidal symptoms, which may be the cause of poor compliance and further addition of anticholinergic agents to treat them, leading to increase in the cost of the therapy as well as associated anticholinergic side effects like dry mouth, constipation, retention of urine etc. Atypical antipsychotics (other than clozapine) are now rated as first line agents for treatment of schizophrenia because their low propensity to cause extra pyramidal side effects (EPS), efficacy against refractory cases and better control over negative symptoms; better tolerance and low relapse rate and safer adverse effect profile. ${ }^{11}$

\section{Observed drug use pattern in various mood disorders}

Among the drugs used for various mood disorders sodium valproate and divalproex were most commonly prescribed agents followed by lithium. Kessing et al, found that, in general, lithium was superior to valproate. ${ }^{12}$ But, because of narrow therapeutic index and lack of presence of therapeutic drug monitoring, its use is less as compared to valproate in this study. In contrast to the present study findings, study conducted by Piparva et al, found that lithium was used extensively in about $73 \%$ of patients diagnosed with bipolar disorders. ${ }^{8}$

\section{Observed drug use pattern in anxiety disorders}

Escitalopram was the most commonly prescribed agents followed by clonazepam in the present study. The 2011 NICE guidelines for the management of anxiety disorders also state that SSRIs or Serotonin Norepinephrine Reuptake Inhibitors (SNRIs) should be offered to the patients first. Benzodiazepines should be avoided and used only for the short term in case of crisis. ${ }^{13,14}$ Clonazepam has become a favoured replacement because it has a longer half-life and empirically elicits fewer withdrawal reactions upon discontinuation. ${ }^{2}$

\section{$A T C / D D D$ classification and $P D D / D D D$ ratio}

When the PDD/DDD ratio is either less than or greater than one, it may indicate that there is either under or over utilization of drugs. ${ }^{2}$ Nevertheless, it is important to note that the PDD can vary substantially between different 
countries, for example, PDDs are often lower in Asian than in Caucasian populations. ${ }^{2}$ DDD mentioned in the table 3 are for the oral route as obtained from the WHO ATC/DDD website 2012 are applicable for management of conditions of moderate intensity and are based on international data. ${ }^{2,15}$ Thus, WHO encourages countries to have their own DDD list based on indigenous data. ${ }^{2}$ PDD/DDD ratio of this study indicates under-utilization of most of the psychotropic drugs and proper utilization of the some of the drugs, which is in contrast to study conducted by Thakkar et al, where most of the drugs were either under or over utilized.

\section{CONCLUSION}

The present study aimed to evaluate drug utilization pattern of psychotropic medicines in tertiary care psychiatry outdoor showed that schizophrenia was the most commonly encountered psychotropic disorder followed by various mood and anxiety disorders. The atypical antipsychotics were most commonly prescribed psychotropic drugs in schizophrenia. Overall rational prescribing has been tried to maintain but, most of the drugs were prescribed by brand name, which should be taken care of and the state EDL has been followed which is appreciable. The PDD/DDD ratio showed the underutilization of the psychotropic drugs, but because prescribing pattern is depending upon the seriousness of the psychotropic illness, prescriptions have been written accordingly. So, as mentioned above that countries should make their own DDD, the present study may help in building the same for bringing the more rationality in prescription of psychotropic medications.

\section{ACKNOWLEDGEMENTS}

We are thankful to Head of the Department, Psychiatry Late BRKM, GMC, Jagdalpur for providing the data and constant support.

\section{Funding: No funding sources}

Conflict of interest: None declared

Ethical approval: The study was approved by the Institutional Ethics Committee

\section{REFERENCES}

1. Mental health in India. Available at: http://www.searo.who.int/india/topics/mental_health/ab out_mentalhealth/en/. Accessed 24 May 2019.

2. Thakkar KB, Jain MM, Billa G, Joshi A, Khobragade AA. A drug utilization study of psychotropic drugs prescribed in the psychiatry outpatient department of a tertiary care hospital. J Clin Diagn Res. JCDR. 2013 Dec;7(12):2759-64.

3. Murthy R. Mental Health Programme in the 11th five year plan. The Indian Journal of Medical Research [Internet]. 2007 [cited 2012 Nov 21];11(June):707-12.
Available at: http://www.ijmr.org.in/article.asp?issn=0971-5916. Accessed 24 May 2019.

4. Sharma P, Das SK, Deshpande SN. An estimate of the monthly cost of two major mental disorders in an Indian metropolis. Indian J Psychiatry. 2006 Jul;48(3):143.

5. WHO International Working Group for Drug Statistics Methodology. Introduction to drug utilization research [Internet]. Geneva: Who collaborating centre for drug utilization research and clinical pharmacology; 2003. Available https://apps.who.int/medicinedocs/en/d/Js4876e/. Accessed 24 May 2019.

6. Agrawal R, Rath B, Saha K, Mohapatra S. Drug utilization pattern of antidiabetic agents in a tertiary care hospital of western Odisha, India. Int $\mathbf{J}$ Basic Clin Pharmacol. 2016;5(5):2222-6.

7. ATC/DDD index 2019[Internet]. WHO collaborating centre for drug statistics methodology. ATC index with DDDs. Oslo:WHO Collaborating Centre for Drug Statistics Methodology; 2002. Available at: https://www.whocc.no/atc_ddd_index/. Accessed 24 May 2019.

8. Piparva KG, Parmar DM, Singh AP, Gajera MW, Trivedi HR. Drug utilization study of psychotropic drugs in outdoor patients in a teaching hospital. Indian J Psychol. Med 2011;33(1):54-8.

9. Sarkar P, Chakraborty K, Misra A, Shukla RK, Swain SP. Pattern of psychotropic prescription in a tertiary care centre: a critical analysis. Indian $\mathrm{J}$ Pharmacol 2013;45(3):270-3.

10. Dutta SB, Dhasmana DC, Bhardwaj R. Psychotropic drug utilization pattern among patients with schizophrenia. Ind J Pschiatry. 2005;47(4):243-4.

11. Dhasmana DC, Rawat Y, Mishra KC. What is so atypical about atypical antipsychotic? Indian J Pharmacol. 2003;35(5):322-4.

12. Kessing LV, Helmund G, Geddes JR, Goodwin GM, Anderson PK. Valproate v. lithium in the treatment of bipolar disorder in clinical practice: observational nationwide register-based cohort study. Br J Psychiatry. 2011;199(1):57-63.

13. Davis KL, Charney D, Coyle JT, Nemeroff C. Neuropsychopharmacology: The fifth generation of progress [Internet]. Philadelphia, Pennsylvania: Lippincott, William and Wilkins; 2002. Available at: http://www.acnp.org/g4/gn401000143/CH140.html.

14. NICE. Anxiety (CG22). National institute of health and clinical excellence. National collaborating centre for mental health; 2011. Available at: http://guidance.nice.org.uk/CG113. Accessed 30 May 2019.

15. ATC/DDD index 2019 [Internet]. WHO collaborating centre for Drug Statistics Methodology Norwegian Institute of Public Health. Available at: http://www.whocc.no/atc_ddd_index/. Accessed 28 May 2019.

Cite this article as: Agrawal R, Marium KA, Sharma RK, Sharma SK, Jaiswal MK. Drug utilization pattern of psychotropic medicines in tertiary care centre of Bastar Region. Int J Basic Clin Pharmacol 2019;8:1891-5. 